\title{
The Effects of Mnemonic Vocabulary Instruction on Content Vocabulary Learning of Students
}

\author{
Parima Fasih \\ Islamic Azad University \\ Correspondence concerning this article should be addressed to Parima Fasih, Department of English \\ Language Teaching, Zanjan Branch, Islamic Azad University, Zanjan, Iran. \\ E-mail: parima_fasih@yahoo.com
}

Siros Izadpanah

Islamic Azad University

Correspondence concerning this article should be addressed to Siros Izadpanah, Department of English Language Teaching, Zanjan Branch, Islamic Azad University, Zanjan, Iran. E-mail: cyrosIzadpanah@yahoo.com

\author{
Ali Shahnavaz \\ Islamic Azad University
}
Correspondence concerning this article should be addressed to Ali Shahnavaz, Department of English Language Teaching, Zanjan Branch, Islamic Azad University, Zanjan, Iran.
E-mail: shahnavaz_ali2000@yahoo.com

\begin{abstract}
The present article is an investigation about the effects of mnemonic vocabulary teaching to improve content vocabulary learning in EFL classrooms. A major issue with the most of the past studies was that they paid little or no attention to the effects of using mnemonic strategies to improve content vocabulary learning. The purpose of this paper is to investigate how key word mnemonic vocabulary teaching can improve the comprehension and learning of the content vocabulary for the students. To this end, 256 third year senior high school students from 6 senior high schools in Zanjan (Iran) were selected through a multistage cluster random sampling method and based on the Cambridge placement test (2010), 230 students proved to be upper intermediate. A quasi-experimental design was used to determine the effects of a mnemonic vocabulary intervention on content vocabulary learning. In this article there were one control group $(A, n=115)$, and one experimental group $(C, n=115)$ all of which were male and there were selected randomly. This study was done in May 2017, and over four weeks, in two thirty-minute sessions per week, group $\mathrm{C}$ received key word mnemonic instruction. In order to test the effects of mnemonic vocabulary teaching on content vocabulary learning, the covariance analysis was employed and the results demonstrated that by eliminating the covariance factor of the pretest, mnemonic vocabulary instruction improved content vocabulary learning for students. The use of keyword mnemonics as a means to differentiate instruction is an educational result that can assist teachers.
\end{abstract}

Keywords: mnemonic vocabulary teaching, content vocabulary learning, EFL classroom, quasiexperimental design, mnemonic instruction, covariance factor

One of the most significant current discussions in learning and teaching is the mnemonic vocabulary technique, which plays a key role in learning a second or foreign language because it connects new learning to prior knowledge through the use of visual or acoustic cues (Abdullah, Mokhtar, Mohamed, Rawian \& Yahaya, 2017). The utilization of mnemonic dates back to $500 \mathrm{~B}$.C and the word mnemonic (pronounced as "ni-mon-iks") is derived from the Greek word "Mnemosyne" or "mnemon", which means mindful, 
alluding to the antiquated Greek goddess of memory (Pillai, 2017; Yates, 1966). The initially utilized mnemonic device was an earlier form of the current technique for loci and from that point forward, various devices have been produced (Amiryousefi \& Ketabi, 2011; Higbee, 1987; Pillai, 2017). Atkinson (1975), the pioneer on this issue, believes that mnemonics is an instructional strategy, that is, techniques or devices intended to help students enhance their memory of vital information that includes teaching students to connect the new data to the information that they already know. Additionally, he believed that our mind is like the London Underground. By this he implies that information stored in the brain is linked in various ways and mnemonics have been proven to be extremely effective in helping people remember things that are linked to each other. One important factor that affects the ease of L2 vocabulary learning involves committing the link between the word's form and its meaning to memory. Accordingly, the general picture of the mental vocabulary is one in which there are varieties of connections between some strong and weak words that we call the weak words "mnemonics" (Amiryousefi \& Ketabi, 2011).

To help language learners tackle this difficulty, several studies about mnemonic strategies have been proposed and used in vocabulary teaching and learning, such as the keyword method, the method of loci, the peg word system, grouping words, words according to semantic relationships, and analyzing the word's structure, studying its affixes and root (Dresler, Fernández, Greicius, Konrad, Müller, Shirer \& Wagner, 2017; Hunt \&Worthen, 2011). The basic types of mnemonic strategies rely on the use of key words, rhyming words, or acronyms. Teachers may develop mnemonic techniques or have students come up with their own. Also, more general studies on this issue were done by several researchers. Wei (2015) tested the effectiveness of the word part technique in comparison with the keyword method and self-strategy learning on university students and the results showed that the keyword method was inferior to the word part technique and self-strategy learning on the translation test format. Pillai (2017) provided information on how visual mnemonics, physical mnemonics and other mnemonic devices can be used in the ESL classroom to improve vocabulary, boost memory, enhance creativity and show that these mnemonic devices help increase the students' self-esteem as well as their learning and using these strategies to make them an independent learner was an ultimate goal of this study.

It is generally agreed that an important part of learning a foreign language is learning its vocabulary. One cannot read, write, speak or comprehend a language without knowing its words. Vocabulary is the most important influence on reading comprehension and student performance. When readers know many content words, they can read more complex texts and they can compose more sophisticated documents. For decades, the value of vocabulary was evident in content standards and most states or provinces typically had a standard related to vocabulary. Content vocabulary are: a range of general academic and domain-specific words and phrases enough for reading, writing, speaking, and listening at the college and career readiness level; represent independence in gathering vocabulary knowledge when considering a word or phrase important to comprehension or expression. Content words are words that have meaning like nouns, main verbs, adjectives and adverbs and they can be compared to grammatical words, which are structural. Also content words refer to terms, concepts or vocabulary having explicit meaning, and are important to understanding particular content. (Baumann, Kame'enui, \& Ash, 2003).

According to Krashen (1993), when students travel, they do not carry grammar books but instead they carry dictionaries. Despite this importance, it seems that from about 1945 to the late 1970s and early 1980s, almost all methods and approaches of language teaching gave vocabulary learning little or no prominence. They saw vocabulary as secondary as something that could simply be left to take care of itself. In other words, little emphasis was placed on the acquisition of vocabulary, a domain largely ignored by most researchers. Since then, however, because of the growing awareness of the importance of vocabulary and vocabulary learning, many studies have tried to deal with different vocabulary learning strategies (e.g. Brown \& Perry, 1991; Fan, 2003; GU \& Johnson, 1996). Some of these vocabulary learning strategies achieved high levels of popularity at different moments in time but then were replaced by other strategies which were claimed to be based on newer or more appealing ideas and theories. What is important here is that whatever these vocabulary learning strategies are, they have one thing in common: all of them, like any other kinds of strategies, are designed to facilitate the acquisition of new information. According to Nation (1982), "what learners do while studying words is more important than how motivated they are, how hard they work, how much time they spend and the number of repetitions of each word" (p. 25). This simple statement can vividly confirm the importance of applying strategies in learning new vocabulary items.

A wealth of research has been documented about mnemonic vocabulary and content vocabulary learning. So far, however, a major limitation of all these studies is that they have not investigated the effects of using mnemonic strategies to improve content vocabulary learning. This article seeks to fill that gap by focusing on the effectiveness of using mnemonic 
vocabulary strategies to content vocabulary learning in the EFL classrooms on 230 third year senior high school students in Zanjan.

The issue of mnemonics (memory improvement techniques) in language learning received some interest in research over 20 years ago but it was not then a modern art. However, in the last 5 years, in particular, the topic has rekindled both theoretical and empirical research interest and yet there is no general agreement about to what extent teaching mnemonic vocabulary would improve students' reading comprehension.

Vocabulary learning was an important component, yet a challenging task, in increasing reading comprehension. This issue requires researchers to undertake investigations in order to find out more about their relationships. An important question overlooked by research is: What kinds of vocabulary learning strategies are more to the benefit of learners who think that the acquisition and recall of vocabulary is their greatest source of problem in learning a foreign/second language? Although an extensive number of studies until now have been conducted to explore this issue, the specific techniques or strategies to teach with are still a matter of considerable controversy. The need for further investigation to fill the remaining gaps in this area remains. To this end, the present paper seeks to investigate the nature of mnemonic vocabulary teaching and its effects on content vocabulary learning by raining the following question, "Does the use of a mnemonic vocabulary instruction improve content vocabulary learning for students?"

\section{Materials and Methods}

Since written material supplies one of the significant sources of knowledge, the capability to comprehend the content material of a written text is vital in the pursuit of academic achievement. Regardless of the current sensitivity in writing at a discourse level, applied linguists have paid very little attention to the content vocabulary itself. It was given that everybody had the ability to read different texts, comprehend the content vocabulary, and also understand its meaning by different methods, so why should this area require research? However, writing forms a complex linguistic system, which is significant to all educated language users, and which must be achieved by all capable individuals in both the first language (L1) and second language (L2) (Cook, 2001). The significance of content vocabulary and understanding written texts requires capable individuals to find out more about different vocabularies, which is especially difficult to master in
English.

\section{Mnemonics}

Mnemonics (mnemonic devices or techniques) are mental aids that assist us in remembering distinctive sorts of items and information; for example, new word forms, names, historical dates, numbers, formulas, and various rules and lists. Regularly, they include recoding or breaking down formal segments of a target (tobe-remembered) item in a manner that makes these segments more familiar, abbreviated, or somehow less demanding to recall (Atkinson, 1975).

\section{Origins, History and Characteristics}

The term mnemonic had its origins in the ancient Greek term mnbmonikós, meaning "related to or of memory" (Mnemosyne was the goddess of memory in Greek mythology). The ancient Greeks had effectively recognized two different types of memory, one that was inborn and "natural" and another that was "artificial" and prepared by means of mnemonic techniques. The history of keyword strategy goes back to 1975 , when Atkinson the pioneer of this subject, used it for teaching Russian vocabulary. Through this experimental study, the strategy expanded to use in schools, particularly to support students with learning disabilities in the 1980s and beyond (Atkinson, 1975). Mnemonic devices can be arranged as "artificial," given the typically arbitrary connection between specific components of a given target item and how they were recoded.

\section{Mnemonic Instruction}

Mnemonic instruction links new information to earlier knowledge by utilizing visual or acoustic cues (Kuder, 2017). Many different strategies are utilized in mnemonic instruction, which are designed to enhance students' memory of new information. The keywords, peg words, and letter strategies work with various combinations and thought processes, but all of them can be utilized to manage facts and information. These distinctive methodologies can be found under different names, such as: imagination, association, and location, however they all have a noteworthy impact in recalling and retrieving new information (Mastropieri \& Scruggs, 2017).

\section{Keyword Method}

Keyword strategies make use of concrete, similar sounding words to help students in the recall of new vocabulary words. For instance, for the term Cold War, the word "hold" could be utilized. This new keyword 
would be associated to an interactive representation that depicts the definition or concept and the keyword as they relate to one another (Marshak, Mastropieri, \& Scruggs, 2011; Piribabadi \& Rahmany, 2014). This type of strategy utilizes earlier knowledge to facilitate meaning of unknown words. Keywords are combined with interactive illustrations that make evident the meaning of the new word (Davoudi \& Yousefi, 2016; Lin, 2014).

\section{Iranian Studies about Mnemonic Vocabulary Teaching and Content Vocabulary Learning}

A wealth of internal studies was done about mnemonic vocabulary teaching and content vocabulary learning, however many queries are as yet unanswered. These examinations have tried to determine the adequacy of a mnemonic strategy to facilitate learning. Davoudi and Taheri (2016) investigated the effect of the keyword method of vocabulary teaching on the learning and long term retention of vocabulary in a normal EFL classroom context. Fifty elementary EFL students were chosen and divided into experimental and control groups. The experimental group received mnemonic keyword vocabulary instruction and the control group received conventional memorizationbased instruction of the same vocabulary items. For each group two post-tests were administered, one test immediately after instruction and one two weeks later. Paired and independent samples t-tests were run on the data and the results showed that participants in the keyword group outperformed the memorization group significantly in both their learning and retention of the vocabulary items. The results of the study confirmed the effectiveness of using mental links and images, through the utilization of mnemonic strategies, for vocabulary learning and retention of elementary level EFL learners.

Keysan, Hasani and Zarei (2013) investigated the effects of selected presentation techniques including the keyword method, the peg word method, the loci method, argument mapping, concept mapping and mind mapping on L2 vocabulary comprehension and production. For this purpose, a sample of 151 Iranian female students from a public pre-university school was chosen on the basis of accessibility. They were divided into six groups. Each group was randomly divided into one of the afore-mentioned treatment conditions. After the experimental period, two post-tests in multiple choice and fill-in-the-blanks formats were administered to estimate the participants' vocabulary comprehension and production. Two independent one-way analysis of variance (Anova) procedures were utilized to investigate the acquired data. The results demonstrated that the differences among the impact of the above-mentioned techniques were statistically important in both vocabulary comprehension and production. These findings can have implications for learners, teachers, and material developers.

Azmi, Najmi and Rouyan (2016) examine the effectiveness of using mnemonic techniques in learning English vocabularies by investigating students' perspectives and points of view of the mnemonic technique in teaching and learning English vocabularies. The selected participants were students learning English in a primary school. Their English teachers instructed them about English vocabulary with and without using the mnemonic technique. A questionnaire was designed by the researchers and administered to the students. The result received from the questionnaire demonstrated the effectiveness of using mnemonic techniques in learning English vocabularies as well as the students' response towards the technique.

Azin, Biriya, Sardabi (2015) investigate the effect of inferring the meaning of new words from context on vocabulary retention by Iranian EFL learners. 67 Iranian university students of Tehran Islamic Azad University participated in this study. They were sophomore English translation students who had participated in a reading comprehension course in two different classes. In order to homogenize the participants, all students took a language proficiency test. One group was assigned randomly as the control group (CG) and the other as the experimental group (EG). A pretest was administered to ensure that the new words were unfamiliar to them. During the 6 sessions of treatment, 48 selected items were presented to the control group in the conventional way. The vocabularies were taught through giving clarification, definition, synonyms or antonym, but in the experimental group, the students inferred the meanings from the context and wrote down their inferences. Afterwards, the surprise posttest was administered in order to evaluate both groups' vocabulary retention. After applying the t-test, the results demonstrated that the experimental group did much better on the final test.

Ashoori and Yazdani Moghadam (2015) attempted to find out the effectiveness of mnemonic devices as a memory strategy on the learners' vocabulary retention. For this purpose, 60 Iranian EFL acquirers at preintermediate level of language proficiency were chosen and participated in this study. There was no limitation regarding their age. In order to homogenize the participants, the researcher implemented Preliminary English Test (PET) as a pretest. The participants were assigned into two groups of 30, experimental and control. Eighty pre-selected words through mnemonic devices were used for the experimental group, while the same vocabularies were taught to the control group through traditional vocabulary instruction.

To answer the first research question, the mean 
scores of both experimental and control groups on the immediate post-test were compared. The result showed that mnemonic devices are more influential than the traditional methods. To answer the second research question, the researcher analyzed the mean scores of the experimental group on the immediate and the delayed post-tests. The result demonstrated that learners' delayed recognition of second language vocabulary is not influenced by the passage of time, implying that words learned via mnemonics instruction were retrieved effectively both in the process of immediate and delayed retention. This study showed that memory strategies like mnemonics are of great application and importance in the process of short and long term retention of EFL learners. Thus, mnemonic devices should be given prime attention by both EFL material developers and instructors as a potentially efficient technique for vocabulary instruction, acquisition, and long term retention in foreign language improvement.

Aidinlou and Mahalle (2013), aimed to study the effects of G5 mnemonic technique on Iranian English language learners' retention of vocabulary items. To do so, 40 Iranian English language learners at the intermediate level were randomly chosen for the study. They were randomly divided into one experimental group and one control group. In order to homogenize the learners, a pre-test was administered and a same test was repeated as post-test after 9 weeks. Both groups were taught about 360 vocabulary items. These vocabulary items were instructed with mnemonic technique (G5) to the experimental group while the control group did not receive any technique. Detailed analysis demonstrated that, there was a significant contrast between experimental and control groups in retention of vocabulary items.

As demonstrated above, most of the previous studies investigated the impact of mnemonic strategies instruction on vocabulary achievement and retention, on the immediate and delayed information retrieval of vocabulary learning, vocabulary improvement, on the learning and long term retention of vocabulary. They also investigated the effect of direct vocabulary learning strategies on reading comprehension skill for university students, and examined two different methods of vocabulary learning, namely the keyword method and context method to investigate their possible effects on vocabulary knowledge, retention, pronunciation and attitudes, to find out the effectiveness of mnemonic devices as a memory strategy on the learners' and retention of vocabulary over the long term. They did all of these investigations on EFL elementary learners, in a normal EFL classroom context, on low-intermediate Iranian EFL learners and on fifth grade primary school students. By contrast, this study investigates the effects of mnemonic and direct vocabulary teaching on the content materials learning of the upper intermediate high school students.

\section{International Studies about Mnemonic Vocabulary Teaching and Content Vocabulary Learning}

Abdullah, Mokhtar, Mohammad, Rawian and Yahaya (2017) identify types of learners based on their VLS preferences and discuss the impact of their preferences on the acquisition of English vocabulary. Seven vocabulary learning strategies namely metacognitive regulation, guessing strategies, dictionary strategies, note-taking strategies, rehearsal strategies, encoding strategies, and activation strategies - were examined. 360 first- and second-year students of University Technology MARA, Perlis, from five degree programmes participated in the study. A vocabulary learning questionnaire developed by $\mathrm{Gu}$ and Johnson (1996) was applied to collect the data. Before using the questionnaire, it was first translated into the Malay language and pilot-tested. Results demonstrated that the participants preferred guessing and dictionary strategies the most; the other five strategies were preferred less.

Philips (2016) examined the effects of picture word pairing and semantic mapping strategies on the vocabulary understanding of second grade students. Fourteen second grade students were provided with an instructor-created pre-test on vocabulary words found in their story for the week. At that point, the instructor improved the usual vocabulary guideline with two visual strategies, picture word pairing and semantic mapping strategies. Lastly, they were given a post-test to assess how much they had improved. Results showed that the intervention enhanced all participants' scores by $15 \%$. Eight out of fourteen had a score of over $80 \%$ on the post-test, suggesting that the visual strategies helped the participants to learn vocabulary.

Basibek and Saricoban (2012) investigated the comparison of the impact of utilizing mnemonics technique by preparing some keywords for students and of the context method on the retention of the vocabulary items. For the purpose of this study, 84 upper-intermediate English students from the Electrical and Electronics Engineering Department at Selcuk University participated in the experiments. The students were divided into two groups to form the experimental and the control groups. Twenty target vocabulary items were utilized in the study. Each group was given a pre-test before the introduction of the new words. The vocabulary items were instructed with mnemonics technique for the experimental group and the control group was introduced with the context method. Immediate recall and recognition tests were used for each group after the treatment. In order to measure long-term retention, delayed recall and 
recognition tests were given to the groups five weeks after the immediate tests. To analyze the distinctions between the mnemonics technique and context method, t-test calculations were used with the results of the pre-tests, immediate and delayed tests. As indicated by the results, the mnemonics technique is more efficient than the context method in immediate and delayed recall and recognition of the vocabulary. Thirteen first year Spanish students enrolled in a rural Midwest school took part in the study.

Bell (2008) set out to determine if the implementation of a specific mnemonic technique would increase foreign language vocabulary recall. A keyword method was implemented in this study as a mnemonic technique. Students' foreign language recall data was analyzed from archival assessments and compared to post-assessments following the implementation of the keyword method. Results showed that students demonstrated an increase in vocabulary recall, particularly when the keyword and the foreign language word were imagined interacting together.

Condus, Marshall and Miller (1986) investigated the effects of the keyword mnemonic strategy on vocabulary acquisition and maintenance by learning disabled children. Sixty-four 12-year-old students identified as learning disabled poor readers were chosen to participate in this study designed to test the efficacy of using an imposed keyword strategy to teach 50 word meanings. Results of the three-way analysis of covariance (ANCOVA) demonstrated that keyword condition students essentially outperformed students assigned to all other conditions.

Most of the previous studies used mnemonics for vocabulary understanding by different mnemonic strategies on the motivation of the learners and in order to teach different words of different fields and to see the impact of mnemonic devices on attainment and recall in basic knowledge acquisition in different fields like nursing. However, there is not much focus on how keyword mnemonic instruction can improve reading comprehension of upper intermediate students and understanding the content materials. Our study explored teachers' and students' attitudes and ideas about using direct or mnemonic vocabulary teaching, while previous studies have been more focused on students' results and di not teach about mnemonic or direct vocabulary teaching.

\section{Participants}

The participants of this study were 230 third year senior high school students in Zanjan. Zanjan province has 8 cities, with Zanjan city chosen for this. Zanjan city has 2 districts, with district two was chosen randomly. In district 2 there were 433 schools that among them senior high schools were randomly chosen. There were 47 senior high schools in district two, 24 of them were for boys and among them, 8 were non-profit. The third level students of 6 senior high schools included: Sama, Shams, Sourosh, kharazmi, Taha and Daneshmand junior high schools were randomly chosen. There were 3 third year classes in each of them and two classes of each were randomly chosen for this study.

The statistical population of this study was 1650 third year junior high school students in the second district in Zanjan. According to Cochron's formula, 245 participants were selected and, in order to increase the accuracy of the study and to have homogeneous groups, $10 \%$ or 10 more participants were added for a total of 256 students participating in this study. Their ages ranged from 15 to 16 , and all were male students. The type of sampling in this study was multistage cluster random sampling. Because of some restrictions due to the rules of the Zanjan Department of Education, and because the researchers needed to have related licenses for performing their research in different schools of Zanjan city, the researchers could only gain the related licenses for male students.

In order to guarantee the homogeneity of the participants of this study and to fulfill the objectives of the study, a Cambridge placement test (2010) by Cambridge University Press was distributed among all the students to determine their level of proficiency. The aim was to select those students with the upper intermediate level of proficiency. Out of 256 students, 230 students were proved to be upper intermediate. After that, the Student's Consent Form was distributed among students in order to make them familiar with the processes of the study. Finally, in order to motivate the students to participate in this study, a notebook was provided to them as a gift.

\section{Pilot Study}

The Cold War Vocabulary Pre- and Post- Assessment and Civil Rights Vocabulary Pre- and Post-Assessment were piloted on 30 students with similar educational backgrounds in order to obtain the reliability for the test. The test-retest reliability of these with the oneweek interval was .82 which showed an acceptable reliability value, because tests that have scores with a reliability of .80 or higher are considered sufficiently reliable for most investigative purposes (Gay, 1992, as cited in Chen, 2006).

\section{Instruments}

1. Cambridge placement test (2010) by Cambridge University Press

2. Cold War Vocabulary Pre- and Post- Assessment 
3. Civil Rights Vocabulary Pre- and Post-Assessment

\section{Cambridge Placement Test}

To have a homogeneous group of participants, to neutralize any effect of proficiency level on participants' performance, and to fulfill the objectives of the study, a Cambridge placement test (2010) by Cambridge University Press was distributed among all the student participants. The aim was to select those students with an upper intermediate level of proficiency.

\section{Vocabulary Tests}

Vocabulary pre-tests, post-tests, and corresponding answer keys were developed by the researcher and the validity and reliability were checked by another researcher with expertise in mnemonics research in Nutt's investigation (2015). These tests were very simple in format. Content words that have been historically difficult for students were chosen by the teachers, in collaboration with the researcher. Twenty words that were to be taught via the mnemonics or traditional vocabulary instruction were included in the vocabulary pre-assessment. This test was in a chart format with the vocabulary word on the left and three blank columns to the right of the word. The first column was labeled, "this means..." The second column was labeled, "I think it means (or is)..." The third column was labeled, "I don't have a clue." Students were instructed to fill in the definitions of the words they knew in the first column. If they thought they knew the definition, but were unsure, they were instructed to fill in the second column. If they did not know the definition, they were instructed to put a check mark in the third column. The answers were considered to be complete and correct if they matched the full answer on the answer key. Those correct answers were awarded one point. A partially correct definition was awarded a half-point. Partial credit was given if enough information was included in the answer so that it could be inferred back to the vocabulary word. Incorrect or blank answers were not awarded any points. The vocabulary post-test was identical to the pre-test.

\section{Procedure}

In this study, two classes from each of the six senior high schools (Shams, Sorosh, Kharazmi, Taha, Daneshmand and Sama) were chosen and assigned randomly into two groups, one control group (A) and one experimental group (C). The English teachers of these six senior high schools assisted the researchers in this study and the researchers showed the teaching procedures of mnemonic method for this study. The teaching materials covered during this intervention was the Cold War era and the Civil Rights movement vocabularies that were validated by Nutt (2015). Then, with the help of the English teachers and the researchers, sessions were held over four weeks, meeting every week in two thirty-minute sessions, with students in experimental group $C$ receiving the key word mnemonic instruction $(\mathrm{n}=115)$ and how to use this technique in reading. For all of the classes, the same pre-tests were used to inform and guide the instruction, focusing on the areas of weakness demonstrated by the students on the assessment. After the students took the pre-tests, results were used to guide content instruction, through the use of PowerPoint slides for all of the experimental groups and they participated in whole group instruction.

\section{Instructional Procedure: Control Group}

During this four-week study, control group A did not receive treatment by the researchers and was then used as a benchmark to measure the other tested subjects' treatment. Like other participants of this study, they were provided with pre- post tests and the results were used to compare the participants of groups $\mathrm{A}$ and $\mathrm{C}$ and to examine the effects of using key word and direct method instruction on content vocabulary learning.

\section{Instructional Procedure: Experimental Group (Key Word Mnemonic Instruction).}

In experimental group C, the EFL teachers of these classes with the help of the researchers and key word mnemonic instruction introduced vocabulary words each session. In key word mnemonic instruction, some cards were presented as a PowerPoint presentation with the teacher introducing each vocabulary word along with the illustration that connected pictorial images of concrete keywords with an action that represented the vocabulary word's definition (Fontana, Mastropieri \& Scruggs, 2007). After that, these cards were printed and given to the students for further studies. Students were directed to take notes in their notebooks, and to ask questions or pose comments. Before the initial mnemonic strategy instruction, at the beginning of class, teachers provided content information with a discussion of material covered previously. The focus of the mnemonic vocabulary instruction was students learning key words in order to understand and learn about the meanings of the words in a reading.

\section{Results}


"Does the use of a mnemonic vocabulary instruction improve content vocabulary learning for students?" To address this question, covariance analysis was used to identify possible correlations between students' performance across the vocabulary pre-test and posttest. The result of covariance analysis was recorded in Table 1.

\section{Normality of the Scores}

One-sample Kolmogorov-Smirnov tests were conducted in order to check the normal distribution of the data. The results are demonstrated in Tables 2 and 3 .

Considering the Sig values obtained in Tables 2 and 3 , all of which were more than $0.05, \mathrm{H} 0$ that was the normality of the variables in the pre and post-test scores being studied at the significance level of 0.05 was accepted.

\section{Homogeneity of the Variances}

In this study, Levene's test was an inferential statistic used to assess the equality of variances for a variable calculated for two or more groups. Some common statistical procedures assume that variances of the populations from which different samples were drawn are equal. In this research, the Levene test was used to check the homogeneity of the variances and the results were presented in Tables 4 and 5 .

Considering the Sig values obtained in Tables 4 and 5 , all of which were more than 0.05 , the $\mathrm{H} 0$

Table 1

Descriptive statistics of the comprehension of content materials in control and experimental groups on pre and post

\begin{tabular}{|c|c|c|c|c|c|c|}
\hline \multicolumn{7}{|c|}{ Descriptive Statistics } \\
\hline Group & & $\mathbf{N}$ & Minimum & Maximum & Mean & Std. Deviation \\
\hline \multirow[t]{3}{*}{ Control } & Pre.V & 115 & .00 & 5.00 & .6391 & .80445 \\
\hline & Post.V & 115 & .00 & 2.50 & .7739 & .71710 \\
\hline & Valid N (listwise) & 115 & & & & \\
\hline \multirow[t]{3}{*}{ Experiment } & Pre.V & 115 & .00 & 5.00 & .6826 & .92795 \\
\hline & Post.V & 115 & 10.00 & 18.50 & 15.0978 & 1.97676 \\
\hline & Valid N (listwise) & 115 & & & & \\
\hline
\end{tabular}

Table 2

The normality of the pre-tests scores in control and experimental groups

\begin{tabular}{lccl}
\hline \multicolumn{1}{c}{ Variables } & Sig & Decision & Results \\
\hline Content vocabulary learning scores of control group & Acceptance of H0 & 0.20 & Distribution is normal \\
\hline Content vocabulary learning scores of experimental group & Acceptance of H0 & 0.20 & Distribution is normal \\
\hline
\end{tabular}

Table 3

The normality of the post-tests scores in control and experimental groups

\begin{tabular}{lccc}
\hline \multicolumn{1}{c}{ Variables } & Sig & Decision & Results \\
\hline Content vocabulary learning scores of control group & Acceptance of H0 & 0.20 & Distribution is normal \\
\hline Content vocabulary learning scores of experimental group & Acceptance of H0 & 0.20 & Distribution is normal \\
\hline
\end{tabular}

Table 4

Homogeneity of variance between control and experimental groups in pre-test

\begin{tabular}{cccc}
\hline Variables & Sig & Decision & Results \\
\hline Content vocabulary learning scores & 0.705 & Acceptance of H0 & Acceptance of the homogeneity of variances \\
\hline
\end{tabular}

Table 5

Homogeneity of variance between control and experimental groups in post-test

\begin{tabular}{cccc}
\hline Variables & Sig & Decision & Results \\
\hline Content vocabulary learning scores & 0.13 & Acceptance of H0 & Acceptance of the homogeneity of variances \\
\hline
\end{tabular}


that was about homogeneity of the variances at the significance level of 0.05 was accepted and therefore the assumption of the homogeneity of the variances of the subjects in the pre and post-tests scores was accepted with the 0.05 level of error.

\section{Covariance Running before Beginning the Study}

This presupposition was followed and the pretest has been performed before the implementation of the independent variable (mnemonic vocabulary instruction).

\section{Homogeneity of the Regression Slope}

To analyze the homogeneity of regression slope, the $F$ value was calculated between covariance and independent variables the results, which are presented in Table 6, show that this index was significant (Sig> 0.05).

Considering the Sig values obtained in Table 6, all of which are more than $0.05, \mathrm{H} 0$ assumed regression line slope homogeneity between covariance and independent variable was accepted at the significance level of 0.05 .

The Linearity of the Correlation of Covariance Variable and Independent Variable
In order to analyze the linearity of the correlation of the covariance variable and independent variable, the $F$ value of the covariance variable was calculated and the results, which are presented in Table 7, show that this index was significant (Sig> 0.05).

Considering the Sig values obtained in Table 7, all of which were less than 0.05 , the $\mathrm{H} 1$, namely the assumption of linearity of the correlation between covariance and independent variable, was accepted at the significance level of 0.05 .

\section{Hypothesis}

For data analysis of the hypothesis, as mentioned before, covariance analysis was used. The necessary assumptions for analysis of covariance were investigated and these assumptions were confirmed. The result of covariance analysis was demonstrated in Table 8.

As shown in Table 8, the value of $\mathrm{F}$ in covariance analysis for meaningful comprehension of comprehension scores was significant and the $\mathrm{H} 0$ was rejected. Therefore, it can be concluded that there was a significant difference between the mean of two groups (control group and experimental group) in the post-test after the adjustment of the pre-test scores. According to the Table 1, the mean of control group in the pre-test was 0.64 and in the post test was 0.77 , while

Table 6

Regression slope homogeneity test between covariance and independent variable

\begin{tabular}{cccc}
\hline Variables & Sig & F test statistics & Results \\
\hline Content vocabulary learning scores & 0.73 & 0.24 & Acceptance of the regression slope homogeneity \\
\hline
\end{tabular}

Table 7

The test of linearity of the correlation of covariance and independent variable

\begin{tabular}{cccc}
\hline Variables & Sig & F test statistics & Results \\
\hline Content vocabulary learning scores in pre-test & 0.13 & Acceptance of H0 & Acceptance of the homogeneity of variances \\
\hline
\end{tabular}

Table 8

The test of linearity of the correlation of covariance and independent variable

\begin{tabular}{|c|c|c|c|c|c|}
\hline \multicolumn{6}{|c|}{ Tests of Between-Subjects Effects } \\
\hline \multicolumn{6}{|c|}{ Dependent Variable: Post.V } \\
\hline Source & Type III Sum of Squares & df & Mean Square & $\mathrm{F}$ & Sig. \\
\hline Corrected Model & $11856.936^{\mathrm{a}}$ & 2 & 5928.468 & 3026.358 & .000 \\
\hline Intercept & 8270.019 & 1 & 8270.019 & 4221.670 & .000 \\
\hline Pre.V & 59.403 & 1 & 59.403 & 30.324 & .000 \\
\hline Group & 11748.047 & 1 & 11748.047 & 5997.130 & .000 \\
\hline Error & 444.680 & 227 & 1.959 & & \\
\hline Total & 26786.563 & 230 & & & \\
\hline Corrected Total & 12301.617 & 229 & & & \\
\hline a. R Squared $=.96$ & ed R Squared $=.964$ ) & & & & \\
\hline
\end{tabular}


the mean of experimental group in the pre-test was 0.68 and in the post-test was 15.10. Considering the significant difference between the post-test scores in the control and experimental groups, it was concluded that by eliminating the covariance factor of the pretest, mnemonic vocabulary instruction improves the content vocabulary learning of the students.

\section{Discussion}

The research question of this paper was: "Does the use of a mnemonic vocabulary instruction at the upper intermediate level improve content vocabulary learning for students?" In the current study, students in experimental group $\mathrm{C}$ received the key word mnemonic instruction $(n=115)$ and how to use this technique in reading. Students in comparison to the control group demonstrated gains on all measures from pre-test to post-test and all students demonstrated improvements, which was the overarching goal of this study. The overall findings determined that there are significant differences in student performance for condition on the pre- and post-tests on both the Cold War and Civil Rights Vocabulary tests.

Content words, or lexical words, are words that carry the content or the meaning of a sentence. In linguistics, content words are words that name objects of reality and their qualities. They signify actual living things, family members, natural phenomena, common, characteristics, etc. They consist mostly of nouns, lexical verbs and adjectives, but certain adverbs can also be content words. Mnemonic vocabulary strategies include keyword tactics that utilize concrete, phonemically similar words to recall new vocabulary words. This paper investigated the effects of mnemonic vocabulary instruction on content vocabulary learning of students.

The methods in the previous papers compared to the methods used here may explain some of the differences in outcomes. Previous mnemonic vocabulary interventions within secondary classrooms were primarily delivered in a one-to-one setting, or small group, while the current paper delivered mnemonic vocabulary instruction among a wide range of students. For example, in the 2007 study by Fontana, Scruggs and Mastropieri, and the 2011 investigation by Marshak and colleagues, the researcher delivered instruction of a researcher developed intervention while in this paper the researchers and the teachers of the classes delivered the instruction which was derived from Nutt's (2015) research and they did not show the effects of mnemonic vocabulary teaching on content vocabulary learning of the third year students.

In another study, Mastropieri, Scruggs, and Fulk
(1990) delivered individualized instruction to twentyfive students in the sixth grade in a two-group design study. The investigation demonstrated the use of keyword images that stratified students by grade level, and randomly assigned them to either the treatment or control condition. The results showed that students in the treatment groups significantly outperformed the students in the control groups. However, the current study demonstrated the use of keyword mnemonic vocabulary in order to understand and learn the content vocabulary.

In another study in the areas of vocabulary development and content knowledge, Seifer and Espin (2012) conducted a research utilizing a withinsubjects design. The researchers examined the effects of text reading, vocabulary learning, and combined approaches to instruction. The vocabulary learning intervention was intended to enhance information of text-specific terms used in a content curriculum class. Because of this direct instruction, when students received instruction that focused on vocabulary learning, performed better on the vocabulary knowledge measures. The results of our research demonstrate that students in comparison to the control group demonstrated a gain on all measures and the effectiveness of mnemonic vocabulary instruction over the direct vocabulary instruction, which the previous studies did not show.

Previous investigations in vocabulary advancement and content vocabulary learning did not yield statistically critical results but the current paper demonstrates the existence of a correlation between mnemonic vocabulary instruction and improvement of content vocabulary learning for students. The practical significance of this research question was to use mnemonic vocabulary technique as a way to improve content vocabulary learning for students in the third level of high school, and to see if it can be used for different levels in different academic places.

\section{Conclusion}

This paper presents an investigation about the effects of using mnemonic vocabulary instruction on content vocabulary learning and shows that the use of a key word mnemonic vocabulary instruction improved content vocabulary learning for third year senior high school students who were very satisfied to use this technique for learning new content vocabulary. Students also showed greater gains on assessments during the mnemonic condition. More importantly, mnemonic vocabulary instruction increased student engagement and motivation toward new vocabularies. Our research adds to the body of literature on the 
use of mnemonics vocabulary strategy instruction and its effects on content vocabulary learning within a wide range of high school students in classrooms. While a large amount of research has been done using mnemonics strategies over the past forty years, further inquiry into the efficacy of this type of intervention in a whole group setting may be valuable. The use of keyword mnemonics has helped different groups of students regardless of whether or not they have a disability. Therefore, mnemonic strategies can be used with all students in inclusive settings in order to learn content information. Teachers require creative strategies they can use in class to help students digest and learn large amounts of content information. The use of mnemonic vocabulary strategies was an excellent tool for delivering content information in a manner accessible to all students.

\section{References}

Amiryousefi, M., \& Ketabi, S. (2011). Mnemonic instruction: A way to boost vocabulary learning and recall. Journal of Language Teaching \& Research, 2(1), 178-182. DOI:10.4304/jltr.2.1.178-182

Atkinson, R. C. (1975). Mnemotechnics in secondlanguage learning. American Psychologist, 30(8), 821-828. DOI: http://dx.doi.org/10.1037/h0077029

Azmi, M. N. L., Najmi, M. H. S. M., \& Rouyan, N. M. (2016). A case study on the effects of mnemonics on English vocabulary. International Journal of Applied Linguistics and English Literature, 5(7), 178185. DOI:10.7575/aiac.ijalel.v.5n.7p.178

Ashoori, P., \& Moghadam, M. (2015). The effect of instructing mnemonic devices on immediate versus delayed vocabulary retention. International Journal of Language Learning and Applied Linguistics World, 8(1), 87-102.

Azin, N., Biriya, R., \& Sardabi, N. (2015). The effect of inferencing the meaning of new words from context on vocabulary retention by Iranian EFL learners. Theory and Practice in Language Studies, 5(6), 12801285. DOI: http://dx.doi.org/10.17507/tpls.0506.22

Abdelhalim, S. M. (2017). Developing EFL students' reading comprehension and reading engagement: Effects of a proposed instructional strategy. Theory and Practice in Language Studies, 7(1), 37-48. DOI: http://dx.doi.org/10.17507/tpls.0701.05

Baumann, J. F., Kame'enui, E. J., \& Ash, G. E. (2003). Research on vocabulary instruction: Voltaire redux. Handbook of research on teaching the English language arts, 2(1), 752-785.

Brigham, F. J., Scruggs, T. E., \& Mastropieri, M. A. (1995). Elaborative maps for enhanced learning of historical information: Uniting spatial, verbal, and imaginal information. The Journal of Special Education, 28(4), 440-460. DOI: https://doi. org/10.1177/002246699502800404

Benge, C., \& Robbins, M. E. (2009). Using keyword mnemonics to develop secondary students' vocabularies: A teacher's action research. Journal of Language and Literacy Education, 6(1), 93-104.

Bell, J. M. (2008). The implementation of the keyword method to increase foreign language vocabulary recall with first year Spanish students (Unpublished Doctoral dissertation), Defiance College, Defiance, Ohio.

Brown, T. S., \& Perry, F. L. (1991). A comparison of three learning strategies for ESL vocabulary acquisition. Tesol Quarterly, 25(4), 655-670. DOI: $10.2307 / 3587081$

Condus, M. M., Marshall, K. J., \& Miller, S. R. (1986). Effects of the keyword mnemonic strategy on vocabulary acquisition and maintenance by learning disabled children. Journal of Learning Disabilities, 19(10), 609-613. DOI: https://doi. org/10.1177/002221948601901006

Chen, Y. M. (2006). The effect of keyword method on English vocabulary long-term retention of elementary school students in Taiwan (Unpublished Master Thesis). Department of Applied English, Southern Taiwan University, Tainan, Taiwan.

Diron, S. S., Eslit, R.E., Reuyan, M. N. (2014). Mnemonic instruction for enhannced comprehension. International Conference on Business, Management \& Corporate Social Responsibility, 2(1), 37-40. DOI: http://dx.doi.org/10.15242/ICEHM.ED0214022

Davoudi, M., \& Ramezani, H. (2014). The effects of cultural familiarity on reading comprehension of Iranian EFL learners. International Journal on Studies in English Language and Literature (IJSELL), 2(8), 58-71.

Davoudi, M., \& Yousefi, D. (2016). The effect of keyword method on vocabulary retention of senior high school EFL learners in Iran. Journal of Education and Practice, 7(11), 106-113.

Dresler, M., Shirer, W. R., Konrad, B. N., Müller, N. C., Wagner, I. C., Fernández, G., \& Greicius, M. D. (2017). Mnemonic training reshapes brain networks to support superior memory. Neuron, 93(5), 1227-1235. DOI: http://dx.doi.org/10.1016/j. neuron.2017.02.003

Fan, M. Y. (2003). Frequency of use, perceived usefulness, and actual usefulness of second language vocabulary strategies: A study of Hong Kong learners. The Modern Language Journal, 87(2), 222-241. DOI: 10.1111/1540-4781.00187

Fontana, J. L., Scruggs, T., \& Mastropieri, M. A. (2007). Mnemonic strategy instruction in inclusive secondary social studies classes. Remedial and Special Education, 28(6), 345-355. DOI: https://doi. 
org/10.1177/07419325070280060401

Gu, Y., \& Johnson, R. K. (1996). Vocabulary learning strategies and language learning outcomes. Language Learning, 46(4), 643-679. DOI: 10.1111/ j.1467-1770.1996.tb01355.x

Higbee, K. L. (1979). Recent research on visual mnemonics: Historical roots and educational fruits. Review of Educational Research, 49(4), 611-629. DOI: https://doi.org/10.3102/00346543049004611

Jalilehvand, M. (2012). The effects of text length and picture on reading comprehension of Iranian EFL students. Asian Social Science, 8(3), 329-337. DOI: http://dx.doi.org/10.5539/ass.v8n3p329

Jangid, N., Swadia, H., \& Sharma, D. (2017). Effectiveness of mnemonic instructions on the thinking strategies of children with learning disability. Journal of Disability Management and Rehabilitation, 2(1), 22-27.

Krashen, S. D. (1993). The case for free voluntary reading. Canadian Modern Language Review, 50(1), 72-82.

Kuder, S. J. (2017). Vocabulary instruction for secondary students with reading disabilities: An updated research review. Learning Disability Quarterly, 40(3), 155-164. DOI: https://doi. org/10.1177/0731948717690113

Lin, G. (2014). Using mnemonic keyword method to help Taiwanese children learn English vocabulary. Journal of Language Teaching and Research, 2(1), 1727. DOI: $10.4304 /$ jltr.2.1.178-182

Mastropieri, M. A., \& Scruggs, T. E. (2017). The inclusive classroom: Strategies for effective differentiated instruction. London, UK: Pearson.

Marshak, L., Mastropieri, M. A., \& Scruggs, T. E. (2011). Curriculum enhancements in inclusive secondary social studies classrooms. Exceptionality, 19(2), 6174. DIO: http://dx.doi.org/10.1080/09362835.2011. 562092

Mokhtar, A. A., Rawian, R. M., Yahaya, M. F., Abdullah, A., \& Mohamed, A. R. (2017). Vocabulary learning strategies of adult ESL learners. The English Teacher, 38(12), 133-145.

Mahalle, M. T. V., \& Aidinlou, N. A. (2013). An investigation of the effects of G5 mnemonic technique in learning vocabulary among Iranian EFL learners. International Journal of Linguistics, 5(2), 224-235.

Naseri, M., \& Zaferanieh, E. (2012). The relationship between reading self-efficacy beliefs, reading strategy use and reading comprehension level of Iranian EFL learners. World Journal of Education, 2(2), 64-75. DOI: https://doi.org/10.5430/wje. v2n2p64

Nutt, K. T. (2015). Mnemonic vocabulary instruction to enhance reading comprehension in the social studies classroom (Unpublished Doctoral dissertation).
College of Education and Human Development (CEHD), George Mason University, Fairfax, Virginia. Piribabadi, A., \& Rahmany, R. (2014). The effect of the keyword method and word-list method instruction on ESP vocabulary learning. Journal of Language Teaching \& Research, 5(5), 1110-1115.DOI:10.4304/ jltr.5.5.1110-1115

Nation, I. P. (1982). Beginning to learn foreign vocabulary: A review of the research. RELC journal, 13(1), 14-36. DOI: https://doi. org/10.1177/003368828201300102

Naeimi, M., \& Foo, T. C. V. (2015). Vocabulary acquisition through direct and indirect learning strategies. English Language Teaching, 8(10), 142151. DOI:10.5539/elt.v8n10p14

Pillai, N. R. (2017). Using mnemonics to improve vocabulary, boost memory and enhance creativity in the ESL classroom. The English Teacher, 38(22), $62-83$.

Phillips, M. (2016). The effects of visual vocabulary strategies on vocabulary knowledge (Unpublished thesis). Marshall University, Huntington, WV.

Reed, D. K., Petscher, Y., \& Foorman, B. R. (2016). The contribution of vocabulary knowledge and spelling to the reading comprehension of adolescents who are and are not English language learners. Reading and Writing, 29(4), 633-657.

Seifert, K., \& Espin, C. (2012). Improving reading of science text for secondary students with learning disabilities: Effects of text reading, vocabulary learning, and combined approaches to instruction. Learning Disability Quarterly, 35(4), 236-247. DOI: 10.1177/0731948712444275

Sariçoban, A., \& Basibek, N. (2012). Mnemonics technique versus context method in teaching vocabulary at upper-intermediate level. Egitim ve Bilim, 37(164), 251-271.

Soleimani, H., \& Hajghani, S. (2013). The effect of teaching reading comprehension strategies on Iranian EFL pre-university students' reading comprehension ability. International Journal of Applied and Basic Sciences, 5(5), 594-600.

Tavassoli, A., Jahandar, S., \& Khodabandehlou, M. (2013). The effect of pictorial contexts on reading comprehension of Iranian high school students: A comparison between pre-vs. during reading activities. Indian Journal of Fundamental and Applied Life Sciences, 3(3), 553-565.

Taheri, A. A., \& Davoudi, M. (2016). The effect of the keyword method on vocabulary learning and longterm retention. International Journal of Language and Linguistics, 3(1), 114-125.

Wei, Z. (2015). Does teaching mnemonics for vocabulary learning make a difference? Putting the keyword method and the word part technique to the test. Language Teaching Research, 19(1), 43-69. 
DOI: https://doi.org/10.1177/1362168814541734

Worthen, J. B., \& Hunt, R. R. (2011). Mnemonology: Mnemonics for the 21st century. New York, NY: Psychology Press.

Yates, F. (1966). The Art of memory. London, UK: Routledge and Kegan Paul Ltd.
Zarei, A. A., Hasani, M. T., \& Keysan, F. (2013). Vocabulary teaching: Mnemonic and mind mapping techniques in focus. Lambert Academic Publishing. Retrieved October 3, 2013 from http:// www.090ad_1367322124key.pdf 


\section{Appendix A}

\section{Iron Curtain}

\section{Cold War Mnemonic Teacher Script}

T: $\quad$ The Iron Curtain was the term used to describe the political and economic separation between communist and free countries. What is the Iron Curtain?

SR: The Iron Curtain is...

T: $\quad$ The keyword for Iron Curtain is a curtain. What is the keyword for Iron Curtain?

SR: The keyword...

T: $\quad$ To remember what the Iron Curtain is, think of the keyword curtain and the strategy illustration of curtains. When I ask what Iron Curtain means, think of the keyword and what is happening in the picture.

What is the Iron Curtain?

SR: The Iron Curtain is...

$\mathrm{T}$ : Good! What is the keyword for Iron Curtain?

SR: The keyword...

T: What is the picture strategy?

SR: The picture...

$\mathrm{T}$ : What is the Iron Curtain?

SR: $\quad \ldots$

T: Great!

$\mathrm{T}$ : What is the Iron Curtain? 


\section{Appendix B}

\section{Civil Rights Mnemonic Teacher Script}

\section{Integrate}

T: Integrate means to end separation of races that any person can go "into" a school, a restaurant, a bus, a movie theatre. Integrate = desegregate. What does integrate mean?

SR: Integrate means...

T: The keyword for integrate is "into". What is the keyword for integrate?

SR: The keyword...

T: To remember what integrate means, think of the keyword "into" and the strategy illustration of the children from different races holding hands. When I ask what integrate means, think of the keyword and what is happening in the picture.

What does integrate mean?

SR: Integrate means...

T: Good! What is the keyword for integrate?

SR: The keyword...

T: What is the picture strategy?

SR: The picture...

$\mathrm{T}$ : What does integrate mean?

SR: $\quad$...

T: Great!

$\mathrm{T}$ : What does integrate mean? 


\section{Appendix C}

\section{Cold War Vocabulary Pre- and Post-Assessment}

\begin{tabular}{l}
\multicolumn{1}{c}{ Vocabulary Word } \\
\hline Iron Curtain \\
\hline Containment \\
\hline Cold War \\
\hline Harry S. Truman \\
\hline Fair Deal \\
\hline Dwight D. Eisenhower \\
\hline George C. Marshall \\
\hline Desegregate \\
\hline Cease Fire \\
\hline Demilitarized Zone \\
\hline Senator Joe McCarthy \\
\hline Arms Race
\end{tabular}

\section{Name:}

Date:

School:

\section{Directions:}

- In the chart above, you will find names and vocabulary that are essential for the unit of study.

- Write your answer in the first box.

- If you are not sure, write what you think the answer is in the second box. If you do not know, put a check mark in the last box. 


\section{Appendix D}

\section{Civil Right Vocabulary Pre- and Post-Assessment}

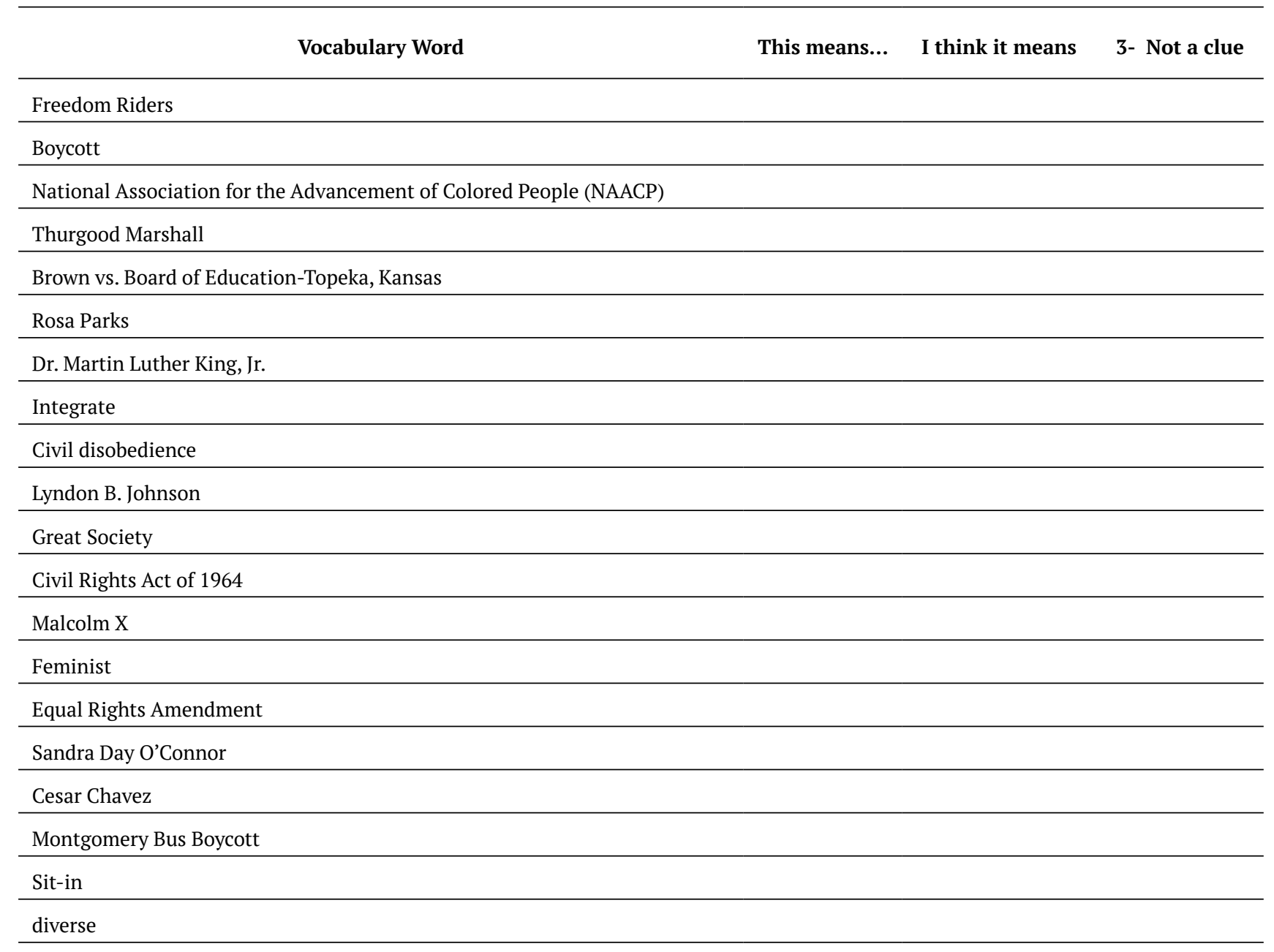

Name:

Date:

School:

\section{Directions:}

- In the chart above, you will find names and vocabulary that are essential for the unit of study.

- Write your answer in the first box.

- If you are not sure, write what you think the answer is in the second box. If you do not know, put a check mark in the last box. 


\section{Appendix E}

\section{Cambridge Placement Test (2010) Proficiency Test}

1) Where
I'm from Russia.

A) you are

B) you

C) are you

2) We have house in Moscow.

A) any

B) a

3) I have two , a boy and a girl.

A) sons

B) daughters

4) I work in a I'm a doctor.

A) hospital

B) hotel C) supermarket

5) This is my brother.

A) Her

B) His

name’s Paul.

6) ___ five people in my family.
A) They are
B) There is
C) There are

C) He's

C ) an

C) children

7) I get up ___ 7 o'clock in the morning.
A) for
B) at
C) in

8) I like apples, but I bananas.

A) don't like $\quad$ B) like

9) Excuse me, speak French?

A) do you B) you do C) you

10) How much are shoes?

A) this B) these

C) that

11) Where are my glasses?

They're the table.
A) at
B) on
C) in

12) My sister tennis very well.
A) plays
B) play
C) playing

13) I usually go to work train.

B) with

C) by

14) I don't see my parents very often they live in South Africa.
A) so
B) but

home yesterday afternoon

15) Rosie stayed

B) at

C) to

16) Last night I

to the cinema.

A) went

B) did go C) was

17) The _ _ is quite expensive but the food there is excellent.
A) film
B) restaurant
C) book

18) Do you want to listen to music or TV?
A) see
B) look
C) watch

19) were you at the weekend?

I was in Scotland.
A) When
B) Where C) What

20) you have a good time at the party?

Yes, it was fun.
A) Did
B) Were
C) Had
21) Are you
English teacher?
A) Maria
B) Marias'
C) Maria’s
22) Bob will meet____ at the airport.
A) us
B) we
C) our
23) I'm going to a concert tonight.
A) Do
B) Are
you like to come?

24) use your dictionary? Sure. Here you are.
A) Could I
B) Could you
C) Do I

25) I like this apartment but the is too expensive for me.
A) money
B) rent
C) cost

26) Excuse me, how do I to the bus station?
A) come
B) get
C) arrive

27) Do you sell stamps?

Yes, we do. How___ do you want?
A) any
B) many
C) much

28) Sorry I'm so late. That's
A) $\mathrm{OK}$
B) great
C) right

29) I'd like ___ milk in my coffee, please.
A) some
B) any
C) a

30) ___ a bus stop near my flat.
A) It's
B) Here's
C) There's

31) Is this a good time to talk? Sorry, no. I___ dinner.
A) cook
B) am cooking
C) cooking

32) I think cycling is more dangerous___ driving.
A) as
B) like
C) than

33) We ___ going to the theatre next Saturday.
A) will
B) do
C) are

34) meet for coffee some time soon.
A) Let's
B) Do you
C) Shall they

35) Kamal has got a holiday home near ___ sea.
A) a
B) the
C) some

36) If you've got a headache, you go home.
A) should
B) did
C) had

37) ___ ever been to New York?
A) Have you
B) Are you
C) Did you

38) I only get about five hours' sleep a night.

That's not
A) enough
B) lot
C) too much

39) Did Amina finish the report?

No. She __ it tomorrow.
A) finishes
B) is going to finish C) finished
40) Paula loves working with children.
A) very
B) really
C) much 
41) Is Ottawa the capital of Canada?

I think
A) is
B) yes
C) so
D) right

42) We never a television when I was a child.

A) have had

B) hadn't

C) had

D) didn't have

43) We paid the restaurant bill credit card.
A) to
B) with
C) on
D) by

44) The last time I____ Joanna was in Paris.
A) have seen
B) saw
C) see
D) was seeing

45) If you money from a friend, you should always pay it back promptly.

A) borrow

B) earn

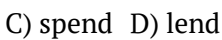

46) Can I make myself a cup of coffee? Of course. You to ask

A) haven't

B) mustn't

C) needn't D) don't have

47) I a lot of sport in my free time.
A) do
B) practise
C) make
D) exercise

48) ___ anywhere interesting recently?
A) Do you go
B) Have you been
C) Are you going D) Will you go

49) It's Walter's birthday on Friday. He___ be 30, I think.
A) should
B) can
$\begin{array}{ll}\text { C) will } & \text { D) shall }\end{array}$

50) Learning the piano isn't as difficult ___ learning the violin.
A) like
B) so
C) than
D) as

51) If the weather__ bad tomorrow, we can go to a museum.
A) will be
B) was
C) is
D) would be

52) About a billion cans of Coca-Cola drunk around the world every day.
A) is
B) are
C) was
D) were

53) My mum's not very well. Oh,

A) it doesn't matter B) I do apologize $\quad$ C) sorry to hear that

D) not bad, thanks.

54) Hans isn't here. He to see his grandmother. He'll be back tomorrow.
A) has gone
B) had been
C) has been $\mathrm{D}$ ) had gone

55) Would you mind changing my appointment? time on Friday is fine.
A) Next
B) All the
C) Every $\quad$ D) Any

56) When I was a child, I climb the wall and jump into our neighbors' garden.
A) would B) did
C) have D) used

57) Have you finished the wall yet?

A) paint B) to paint

C) painting

D) painted

58) Can you help me? I've tried___ hotel in the city and can't find a room.

$\begin{array}{llll}\text { A) many } & \text { B) any } & \text { C) every } & \text { D) all }\end{array}$

59) Lena used to find work boring___ she became a nurse.

$\begin{array}{lll}\text { A) unless B) until } & \text { C) if } & \text { D) since }\end{array}$

60) If I____ closer to my office, I could walk to work.
A) lived
B) would live
C) had lived D) live

61) I__ outside the cinema when suddenly a police car arrived.
A) stood B) was standing
C) have stood
D) am standing

62) Shall we go to The Riceboat for dinner? It be fully booked.

They're sometimes busy on a Monday.
A) will
B) may
C) can
D) must

63) We've come back from a trip to India. It was amazing.
A) already
B) yet
C) just
D) only

64) I've got to be at work in five minutes. Don't worry, I you a lift if you want.
$\begin{array}{lll}\text { A) give } & \text { B) am giving }\end{array}$
C) 'll give
D) 'm going to give

65) My doctor advised me more exercise.
A) take
B) taking
C) having taken
D) to take

66) I couldn't the countryside.
A) put
D) take up 67) There's no name on this dictionary. It
Mine's got my name on the front.
A) might not
B) mustn't
C) won't D) can't

68) Julia married since she was 20 .
A) is
B) was
C) has been
D) is being

69) Don't worry if I____ late tonight. I'm going to the gym after work.
A) am
B) will be
C) would be
D) was

70) I've got a terrible headache, and it won't go away. Have you tried___ some aspirin?
A) to take
$\begin{array}{ll}\text { B) take } & \text { C) took }\end{array}$
D) taking

71) Boxing is a sport__ requires a lot of speed and fitness.
A) it
B) that
C) what
D) where

72) Jon___ working on this project for a couple of months so he hasn't made much progress yet.
A) is only
B) has only been
C) was only
D) had only been

73) I was wondering____ I could ask you some questions.

Sure, go ahead.
A) what B) if
C) that
D) how

74) What clothes should I pack for a trip to Boston? Well, it depends___ the time of year that you go.

$\begin{array}{llll}\text { A) on } & \text { B) with } & \text { C) up } & \text { D) to }\end{array}$

75) I've finished this salad and I'm still hungry. I ordered something more filling.

$\begin{array}{llll}\text { A) must have } & B \text { ) would have } & C \text { ) should have } & D \text { ) may have }\end{array}$

76) Do you ever ask your neighbours to do favours you?
A) for
B) to
C) with D) about over time.

77) Some married couples seem to get more $\begin{array}{llll}\text { A) alike } & \text { B) same } & \text { C) like } & \text { D) equal }\end{array}$

78) I don't know how much this card costs. The price label's off. $\begin{array}{llll}\text { A) gone } & \text { B) taken } & \text { C) done } & \text { D) come }\end{array}$

79) Ben got the job because he a very good impression at his interview.
A) made B) did
C) put
D) took

80) Salsa music always me of my trip to Cuba.
$\begin{array}{lll}\text { A) remembers } & \text { B) realizes }\end{array}$
C) recognizes
D) reminds

81) I___ to be picking Tom up at the station but I've lost my keys. $\begin{array}{llll}\text { A) am supposed } & \text { B) am requested } & \text { C) am intended } & \text { D) am obliged }\end{array}$ 


\section{THE EFFECTS OF MNEMONIC VOCABULARY INSTRUCTION}

82) How about going to Colors nightclub? There's no I'm going there. It's awful!
A) hope B) way
C) time
D) opportunity

83) By the age of 18 , I___ not to go to university.

$\begin{array}{llll}\text { A) had decided } & \text { B) decided } & \text { C) have decided } & \text { D) was deciding }\end{array}$

84) I'm afraid your car repaired before next week.
A) hasn't been B) wasn't
C) wouldn't be
D) can't be

85) The amount of organically grown food on sale has enormously in recent years.
A) raised B) lifted $\quad$ C) increased
D) built

86) Can you believe it? A woman has been the computer of her online virtual husband.
$\begin{array}{lll}\text { A) accused } & \text { B) suspended }\end{array}$
C) arrested
D) suspected

87) You may borrow my laptop

you promise to look after it.
A) unless
B) in case

88) It's a huge painting. It___ taken ages to complete.

$\begin{array}{llll}\text { A) must have } & \text { B) can't have } & \text { C) should have } & \text { D) won't have }\end{array}$

89) Pierre tends to put dealing with problems, rather than dealing with them immediately.

$\begin{array}{llll}\text { A) down } & \text { B) off } & \text { C) over } & \text { D) away }\end{array}$

90) If the taxi hadn't stopped for us, we standing in the rain $\begin{array}{llll}\text { A) were still } & \text { B) would still be } & \text { C) are still } & \text { D) will still be }\end{array}$

91) My mother's Italian, so the language has been quite easy for me.
A) to learn
B) learn
C) having learned
D) learning

92) I had the talent, I still wouldn't want to be a movie star. A) In case B) Even if C) Provided that D) However much

93) The factory workers threatened on strike if they didn't get a pay rise.

$\begin{array}{llll}\text { A) going } & \text { B) to go } & \text { C) that they go } & \text { D) to have gone }\end{array}$

94) I was about to go to sleep when it to me where the missing keys might be.
A) remembered
B) happened
C) appeared
D) occurred

95) There's going to be a new department at work. They've asked me to __ it up.
A) take B) set
C) put
D) bring

96) If the film is a success, the director will get most of the credit.
A) big
B) high
C) large
D) good

97) By the end of today's seminar I will to each of you individually.

$\begin{array}{llll}\text { A) speak } & \text { B) have spoken } & \text { C) be speaking } & \text { D) have been speaking }\end{array}$

98) This is a photo of my little sister ice cream on the beach

$\begin{array}{lll}\text { A) eat } & \text { B) eating } & \text { C) was eating }\end{array}$

D) having eaten

99) Our students take their responsibilities very
A) considerably
B) thoroughly
C) seriously
D) strongly

100 Pia was___ delighted with the birthday present.
$\begin{array}{lll}\text { A) very } & \text { B) completely }\end{array}$
C) fairly
D) absolutely

101) People were amazed that the burglary took place in daylight.
A) wide
B) broad
C) large
D) open

102) She invested a lot of time appropriate university course.
A) to
B) for
C) with

researching the most

103) The police claimed that they acted in self-
A) interest
B) confidence
C) defense
D) discipline

104) I___ remember putting my briefcase down on that shelf.
A) deeply
C) clearly
D) strongly

B) entirely

105) He turned

to be considerably older than I had imagined.

$\begin{array}{llll}\text { A) over } & \text { B) up } & \text { C) out } & \text { D) round }\end{array}$

106) The windows in this house are in urgent of replacement. $\begin{array}{llll}\text { A) need } & \text { B) help } & \text { C) want } & \text { D) demand }\end{array}$

107) Speed cameras shown to reduce accidents.
$\begin{array}{lll}\text { A) have } & \text { B) were being }\end{array}$
C) have been
D) are being

108) Life is a deal easier for immigrants who can speak the local language.
A) far
B) huge
C) big
D) great

109) The experiment testing people's responses before and after drinking coffee.
A) contained
B) incorporated
C) involved
D) consisted

110) We may be a bit late. We're in a traffic jam.

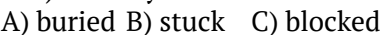

D) surrounded

111) Having his driving test several times, Paul finally passed at the fourth attempt.
A) taken B) made
C) had
D) attended

112) Gospel music has been a major influence styles, especially soul.
A) with
B) to
C) about
D) on

113) Maintaining an accurate balance sheet is essential, business you're in.
A) however
B) wherever
C) whatever
D) whenever

114) It's _ likely that this novel will win a literary prize.
A) totally B) deeply
C) strongly
D) highly

115) It's no him tonight.
A) point
B) wonder
C) secret
D) problem

116) I'd lived in Australia, so I was used to on the left side of the road.
A) driving
B) drive
C) having driven
D) drove

117) I don't think the colours in Julia's outfit
A) fit
B) suit
C) match
D) go together.

118) Very rarely __ here in July.

$\begin{array}{llll}\text { A) it rains } & \text { B) does it rain } & \text { C) is it raining } & \text { D) it is raining }\end{array}$

119) I prefer to buy CDs download music from my computer. $\begin{array}{llll}\text { A) in contrast to } & \text { B) as opposed to } & \text { C) rather than } & \text { D) in }\end{array}$ comparison to

120) The number of turtles on the island by $70 \%$ over the last decade.
A) has declined
B) has been declining $\quad$ C) has been declined 


\section{English}

Unlimited Placement test

\section{Written Test Key}

\begin{tabular}{|c|c|c|c|c|c|c|c|c|c|c|}
\hline \multicolumn{2}{|c|}{ Starter } & \multicolumn{2}{|c|}{ Elementary } & \multicolumn{2}{|c|}{ Pre-int. } & \multicolumn{2}{|c|}{ Intermediate } & \multicolumn{2}{|c|}{ Upper Int. } & Advanced \\
\hline 1 & $\mathrm{C}$ & 21 & $\mathrm{C}$ & 41 & $\mathrm{C}$ & 61 & B & 81 & A & $101 \mathrm{~B}$ \\
\hline 2 & $\mathrm{~B}$ & 22 & A & 42 & $\mathrm{C}$ & 62 & $\mathrm{~B}$ & 82 & $\mathrm{~B}$ & $102 \mathrm{D}$ \\
\hline 3 & $\mathrm{C}$ & 23 & $\mathrm{C}$ & 43 & $\mathrm{D}$ & 63 & $\mathrm{C}$ & 83 & A & $103 \mathrm{C}$ \\
\hline 4 & $\mathrm{~A}$ & 24 & $\mathrm{~A}$ & 44 & $\mathrm{~B}$ & 64 & $\mathrm{C}$ & 84 & $\mathrm{D}$ & $104 \mathrm{C}$ \\
\hline 5 & $\mathrm{~B}$ & 25 & $\mathrm{~B}$ & 45 & $\mathrm{~A}$ & 65 & $\mathrm{D}$ & 85 & $\mathrm{C}$ & $105 \mathrm{C}$ \\
\hline 6 & $\mathrm{C}$ & 26 & $\mathrm{~B}$ & 46 & $\mathrm{D}$ & 66 & $\mathrm{~A}$ & 86 & $\mathrm{C}$ & $106 \mathrm{~A}$ \\
\hline 7 & $\mathrm{~B}$ & 27 & $\mathrm{~B}$ & 47 & $\mathrm{~A}$ & 67 & $\mathrm{D}$ & 87 & $\mathrm{C}$ & $107 \mathrm{c}$ \\
\hline 8 & $\mathrm{~A}$ & 28 & $\mathrm{~A}$ & 48 & $\mathrm{~B}$ & 68 & $\mathrm{C}$ & 88 & A & $108 \mathrm{D}$ \\
\hline 9 & $\mathrm{~A}$ & 29 & $\mathrm{~A}$ & 49 & $\mathrm{C}$ & 69 & $\mathrm{~A}$ & 89 & B & $109 \mathrm{C}$ \\
\hline 10 & $\mathrm{~B}$ & 30 & $\mathrm{C}$ & 50 & $\mathrm{D}$ & 70 & $\mathrm{D}$ & 90 & $\mathrm{~B}$ & $110 \mathrm{~B}$ \\
\hline 11 & $\mathrm{~B}$ & 31 & $\mathrm{~B}$ & 51 & $\mathrm{C}$ & 71 & B & 91 & $\mathrm{D}$ & $111 \mathrm{~A}$ \\
\hline 12 & $\mathrm{~A}$ & 32 & $\mathrm{C}$ & 52 & $\mathrm{~B}$ & 72 & $\mathrm{~B}$ & 92 & $B$ & $112 \mathrm{D}$ \\
\hline 13 & $\mathrm{C}$ & 33 & $\mathrm{C}$ & 53 & $\mathrm{C}$ & 73 & $\mathrm{~B}$ & 93 & $B$ & $113 \mathrm{C}$ \\
\hline 14 & $\mathrm{C}$ & 34 & A & 54 & $\mathrm{~A}$ & 74 & $\mathrm{~A}$ & 94 & $\mathrm{D}$ & $114 \mathrm{D}$ \\
\hline 15 & $\mathrm{~B}$ & 35 & $\mathrm{~B}$ & 55 & $\mathrm{D}$ & 75 & $\mathrm{C}$ & 95 & $\mathrm{~B}$ & $115 \mathrm{D}$ \\
\hline 16 & A & 36 & A & 56 & A & 76 & $\mathrm{~A}$ & 96 & A & $116 \mathrm{~A}$ \\
\hline 17 & $\mathrm{~B}$ & 37 & $\mathrm{~A}$ & 57 & $\mathrm{C}$ & 77 & $\mathrm{~A}$ & 97 & $\mathrm{~B}$ & $117 \mathrm{D}$ \\
\hline 18 & $\mathrm{C}$ & 38 & $\mathrm{~A}$ & 58 & $\mathrm{C}$ & 78 & $\mathrm{D}$ & 98 & $B$ & $118 \mathrm{~B}$ \\
\hline 19 & $\mathrm{~B}$ & 39 & $\mathrm{~B}$ & 59 & $\mathrm{~B}$ & 79 & $\mathrm{~A}$ & 99 & $\mathrm{C}$ & $119 \mathrm{C}$ \\
\hline 20 & A & 40 & B & 60 & A & 80 & $\mathrm{D}$ & 100 & D & $120 \mathrm{~A}$ \\
\hline
\end{tabular}

